Research paper

\title{
Production of medium-chain carboxylic acids by anaerobic fermentation of glycerol using a bioaugmented open culture
}

\author{
Rosemeri I. Dams ${ }^{a}$, Michael B. Viana ${ }^{b}$, Alexandre A. Guilherme ${ }^{a}$, Camila M. Silva ${ }^{c}$, \\ André B. dos Santos ${ }^{\mathrm{d}}$, Largus T. Angenent ${ }^{\mathrm{e}}$, Sandra T. Santaella ${ }^{\mathrm{b}}$, Renato C. Leitão ${ }^{\mathrm{a}, *}$ \\ a Embrapa Agroindústria Tropical, Rua Dra. Sara Mesquita, 2270, Fortaleza, CE, 60511-110, Brazil \\ ${ }^{\mathrm{b}}$ Institute of Marine Science, Federal University of Ceará, Avenida da Abolição, 3207, Fortaleza, CE, 60165-081, Brazil \\ ${ }^{\mathrm{c}}$ State University of Maranhão, Fishing Engineering Department, Cidade Universitária Paulo VI, São Luís, MA, Brazil \\ ${ }^{\mathrm{d}}$ Department of Hydraulics and Environmental Engineering, Federal University of Ceará. Bloco 713, Centro de Tecnologia, Campus do Pici, UFC, Fortaleza, CE, 60451- \\ 970, Brazil \\ e Centrum for Applied GeoSciences, University of Tübingen, Hölderlinstr. 12, Tübingen, 72074, Germany
}

\section{A R T I C L E I N F O}

\section{Keywords:}

Glycerol

Anaerobic digestion

Carboxylate platform

Chain elongation

Bioaugmentation

Clostridium acetobutylicum

\begin{abstract}
A B S T R A C T
Biological production of carboxylic acids during glycerol fermentation via the chain elongation process was investigated. Glycerol is a by-product of the biodiesel production process and a convenient feedstock alternative for the carboxylate platform. In batch experiments, glycerol was used as substrate, whereas sludge (granular and flocculent) and ruminal liquid served as inocula. To improve the production of carboxylates, bioaugmentation with Clostridium acetobutylicum ATCC 824 was performed. Maximal production of $n$-caproic and $n$-caprylic acids was achieved with the use of the granular sludge. Bioaugmentation with $C$. acetobutylicum enhanced production of $n$-caproic acid in the presence of $100 \mathrm{mM}$ ethanol. However, increasing ethanol concentration to $200 \mathrm{mM}$ had no further enhancing effect on $n$-caproic production with or without bioaugmentation. The enhancement of $n$ caproic acid production was probably due to the increased production of $n$-butyric acid by $C$. acetobutylicum, because $n$-butyric acid is an important intermediate in the chain elongation process when ethanol is used as an electron donor.
\end{abstract}

\section{Introduction}

Glycerol is a by-product of the biodiesel production process and is derived from the transesterification reaction of oils from oilseeds and animal fats [1]. Despite residual glycerol is already used by the chemical industry, the increased demand for biodiesel may lead to an overproduction of this by-product. Biodiesel industry generates about $1 \mathrm{~kg}$ of glycerol per $10 \mathrm{~kg}$ of produced biodiesel [2]. According to the Organization for Economic Co-operation and Development (OECD) and the Food and Agriculture Organization (FAO) of the United Nations [3], approximately $3.2 \times 10^{6}$ tons of glycerol have been generated from biodiesel production in 2015 worldwide [3]. Furthermore, an increase to about $3.8 \times 10^{6}$ tons is predicted for 2024 , so alternative uses of this by-product must be developed.

Pure glycerol can be used by the food, pharmaceutical, chemical, and cosmetics industries [4]. Non-purified (residual) glycerol seems to be a promising feedstock to biological processes, because it contains a high organic matter fraction (chemical oxygen demand [COD] of $\sim 1260 \mathrm{~g} \mathrm{~L}^{-1}$ ) [5], and is highly available on the market at low cost. Alternative uses of residual glycerol have been investigated for producing renewable energy via synthesis of hydrogen [1], methane [6], ethanol [7], butanol [8], as well as a variety of chemicals, such as 1,2propanediol [2], 1,3-propanediol (1,3-PD) [9], 2,3-butanediol [10], and organic acids [11]. However, to the best of our knowledge, this is the first report regarding the production of medium-chain carboxylic acids (MCCAs), which are organic acids with 6-12 carbons, using residual glycerol as substrate.

MCCAs are used in the production of fragrances, pharmaceuticals, feed additives, antimicrobials, lubricants, rubbers, and dyes [12]. Among MCCAs, $n$-caproic acid, with a chain of 6 carbons, is a bio-based precursor of biofuel [13], and can be used as flavorants [14], and supplements in swine and poultry feed for control of enteric diseases [15]. Traditionally, $n$-caproic acid is produced via a petrochemical platform or extracted from oil seeds. However, the biological synthesis can be a more environmentally friendly alternative [14]. Recently, production of $n$-caproic and $n$-caprylic acids by an open culture from

\footnotetext{
* Corresponding author.

E-mail address: renato.leitao@embrapa.br (R.C. Leitão).
} 
the granular sludge withdrawn from an upflow anaerobic sludge blanket (UASB) reactor was reported [16]. Agler and collaborators [17] achieved a high rate of $n$-caproic acid production that exceeded $2 \mathrm{~g} \mathrm{~L}^{-1} \mathrm{~d}^{-1}$ using open microbial cultures. According to Spirito and coauthors [18], the use of mixed culture was chosen due its several advantages, i.e. non-sterile environment; easily adaptable microorganism consortia to various substrates; ability to operate in a (semi)-continuous mode.

The biological production of $n$-caproic acid can occur by the carboxylic chain elongation process, in which short-chain carboxylic acids are converted to MCCAs with six or eight carbon atoms [19] via the reverse ß-oxidation metabolic pathway [20]. Equations (1) and (2) show the conversion of acetic acid and ethanol to $n$-butyric acid and then, to $n$-caproic acid [19]. Although it is thermodynamically possible, this reaction is not energetically self-sufficient because not enough adenosine triphosphate (ATP) is formed. Coupled with the biochemical pathway described in Equation (3), one mol of ATP has to be obtained from the oxidation of ethanol [18]. The latter reaction generates sufficient energy for producing $n$-butyric and $n$-caproic acids (Equations (1) and (2)). The whole process produces free Gibbs energy $\left(\Delta G^{\circ}\right)$ of $-366.0 \mathrm{~kJ}$, and $5 \mathrm{~mol}$ of $n$-caproic acid (Equation (4)), resulting in $73.2 \mathrm{~kJ} \mathrm{~mol}^{-1}$ of produced $n$-caproic acid.

If other substrates, such as glycerol, are the only carbon source and energy, it would be necessary to include preliminary fermentation for producing the chain elongation precursors (acetic acid and/or $n$-butyric acid and ethanol), which is shown in Equation (5) [21]. Several studies have reported high yields of acetic and $n$-butyric acids, and ethanol from crude glycerol [22,23]. Coupled with the biochemical pathway described in Equation (5), six mols ATP and four mols of $\mathrm{NADPH}_{2}$ are generated, which can be used for providing energy for the reactions of Equations (1) and (2) without oxidation of ethanol. In this case, more ethanol, which serves as the electron donor for the chain elongation process, is available.

$\mathrm{C}_{2} \mathrm{H}_{5} \mathrm{OH}+\mathrm{CH}_{3} \mathrm{COOH} \rightarrow \mathrm{C}_{3} \mathrm{H}_{7} \mathrm{COOH}+\mathrm{H}_{2} \mathrm{O} \Delta \mathrm{G}^{\prime}=-38.6 \mathrm{~kJ} \cdot \mathrm{mol}^{-1}$

$\mathrm{C}_{2} \mathrm{H}_{5} \mathrm{OH}+\mathrm{C}_{3} \mathrm{H}_{7} \mathrm{COOH} \rightarrow \mathrm{C}_{5} \mathrm{H}_{11} \mathrm{COOH}+\mathrm{H}_{2} \mathrm{O} \Delta \mathrm{G}^{\prime}=-38.8 \mathrm{~kJ} \cdot \mathrm{mol}^{-1}$

$\mathrm{C}_{2} \mathrm{H}_{5} \mathrm{OH}+\mathrm{H}_{2} \mathrm{O} \rightarrow \mathrm{CH}_{3} \mathrm{COOH}+2 \mathrm{H}_{2} \Delta \mathrm{G}^{\prime}=+10.5 \mathrm{~kJ}^{\prime} \mathrm{mol}^{-1}$

$12 \mathrm{C}_{2} \mathrm{H}_{5} \mathrm{OH}+3 \mathrm{CH}_{3} \mathrm{COOH} \rightarrow 5 \mathrm{C}_{5} \mathrm{H}_{11} \mathrm{COOH}+4 \mathrm{H}_{2}+8 \mathrm{H}_{2} \mathrm{O} \Delta \mathrm{G}$

$4 \mathrm{C}_{3} \mathrm{H}_{5}(\mathrm{OH})_{3}+\mathrm{H}_{2} \mathrm{O} \rightarrow \mathrm{CH}_{3} \mathrm{COOH}+\mathrm{C}_{3} \mathrm{H}_{7} \mathrm{COOH}+\mathrm{C}_{2} \mathrm{H}_{5} \mathrm{OH}+4 \mathrm{CO}_{2}$

$$
+4 \mathrm{H}_{2} \Delta \mathrm{G}^{\prime}=+10.5 \mathrm{~kJ}^{\prime} \mathrm{mol}^{-1}
$$

Very few currently isolated microorganisms can synthetize $n$-caproic acid, and among them are Eubacterium pyruvativorans [24], Megasphaera elsdeni [25], Clostridium sp. BS-1 [26], and Clostridium kluyveri [27]. Despite production of $n$-caproic acid by other microorganism, the most well-known producer is C. kluyveri $[14,28]$. When complex substrates are used as carbon and energy sources, other species in the open culture are needed to produce the precursors (acetic and $n$ butyric acids) for chain elongation. Therefore, one way to improve the carboxylic chain elongation process could be by the addition of a culture of a specific microorganism in a process referred to as bioaugmentation. This procedure has been used for increasing methane and hydrogen production with archaeal, facultative, and acidogenic microorganisms $[29,30]$.

This work aimed to improve medium-chain carboxylic acids production (with emphasis in $n$-caproic acid) in batch mode process by biological route deviation using a bioaugmented mixed culture and residual glycerol as feedstock. The process was evaluated by using different sources of inoculum, bioaugmentation with Clostridium acetobutylicum ATCC 824, and utilizing different concentrations of ethanol used as the electron donor. Finally, the microbial community present in the inocula was assessed using denaturing gradient gel electrophoresis (DGGE) of the PCR products.

\section{Material and methods}

\subsection{Glycerol source}

Residual glycerol as substrate was kindly provided by Petrobras from the Quixadá Biodiesel Production Plant, State of Ceará, Quixadá, Brazil. There, glycerol was generated from transesterification of soybean oil (56\%) and beef tallow (44\%). The resulting product had the following chemical composition: glycerol $78.4 \%$, methanol $3.0 \%$, nonglycerol organic matter $1.2 \%$, ashes $4.8 \%$, and moisture $12.6 \%$. The concentration of sodium chloride was $4.8 \%$, which is an indication that ashes was due to $\mathrm{NaCl}$. The chemical oxygen demand (COD) concentration was $1374 \mathrm{~g} \mathrm{~L}^{-1}$.

\subsection{Inocula and microorganism for bioaugmentation}

Three different sources of inoculum were used: 1) flocculent sludge (FS) withdrawn from a UASB reactor treating municipal wastewater containing total volatile solids (TVS) of $55 \mathrm{~g} \mathrm{~L}^{-1}$; 2) granular sludge (GS) withdrawn from a UASB reactor treating brewery effluent containing TVS of $26 \mathrm{~g} \mathrm{~L}^{-1}$; and 3) goat ruminal liquid obtained by stomach tubing (RL) containing TVS of $34 \mathrm{~g} \mathrm{~L}^{-1}$.

C. acetobutylicum ATCC 824 was purchased from the American Type Culture Collection (ATCC). Stock cultures were maintained as suspensions in $30 \%$ glycerol and stored at $-80^{\circ} \mathrm{C}$. The stock culture was transferred to the activating Reinforced Clostridial Medium with the following composition ( $\mathrm{g} . \mathrm{L}^{-1}$ ): glucose (5), beef extract (10), peptone (10), sodium chloride (5), yeast extract (3), sodium acetate (3), soluble starch (1), L-cysteine hydrochloride (0.5), and agar (0.5). Activation was carried out for $72 \mathrm{~h}$ at $\mathrm{pH} 7.0$, and temperature of $37^{\circ} \mathrm{C}$. After activation, $10 \%(\mathrm{v} / \mathrm{v})$ of this culture was transferred to the inoculum Clostridium Growth Medium (CGM), containing residual glycerol $\left(5 \mathrm{~g} \mathrm{~L}^{-1}\right)$ as the main sources of carbon and energy, and the following constituents (g.L $\left.{ }^{-1}\right)$ : $\left(\mathrm{NH}_{4}\right)_{2} \mathrm{SO}_{4}(2.0), \mathrm{K}_{2} \mathrm{HPO}_{4}(2.4), \mathrm{KH}_{2} \mathrm{PO}_{4}$ (1.8), $\mathrm{Na}_{2} \mathrm{HPO}_{4}(0.6), \mathrm{MgSO}_{4}(0.1)$, and $1 \mathrm{mLL}^{-1}$ of trace elements solution

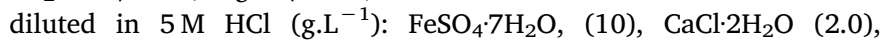
$\mathrm{ZnSO}_{4} \cdot 5 \mathrm{H}_{2} \mathrm{O} \quad(2.0), \quad \mathrm{MnSO}_{4} \cdot 4 \mathrm{H}_{2} \mathrm{O} \quad(0.5), \quad \mathrm{CuSO}_{4} \cdot 5 \mathrm{H}_{2} \mathrm{O} \quad$ (1.0), $\left(\mathrm{NH}_{4}\right)_{6} \mathrm{Mo}_{7} \mathrm{O}_{24} \cdot 4 \mathrm{H}_{2} \mathrm{O}(0.1)$, and $\mathrm{Na}_{2} \mathrm{~B}_{4} \mathrm{O}_{7} \cdot 10 \mathrm{H}_{2} \mathrm{O}(0.02)$. Cells were grown in anaerobic conditions created by saturation of the medium and headspace by $\mathrm{N}_{2}$ gas for $1 \mathrm{~min}$, harvested during the exponential growth phase (based on the optical density at $600 \mathrm{~nm}$ ), and used to inoculate the bioreactors.

\subsection{Experimental set-up}

Serum 250-mL flasks with the working volume of $100 \mathrm{~mL}$ equipped with rubber stoppers and aluminum caps were used as bioreactors. All flasks were filled with CGM as the cultivation medium at an initial $\mathrm{pH}$ of 6.5 , and $10 \mathrm{~g}$ of the mixed culture. Cellular suspension of $1 \mathrm{~g} \mathrm{~L}^{-1}$ of C. acetobutylicum ATCC $824(10 \% \mathrm{v} / \mathrm{v})$ was used for the bioaugmentation assays. Ethanol (100 or $200 \mathrm{mM})$ was added as the electron donor to allow $n$-butyric and $n$-caproic acid synthesis [16]. To inhibit methanogenic activity, a chemical treatment with a $0.05 \%$ chloroform solution was used [31]. Anaerobic environment in the serum flasks was created by saturating the headspace with $\mathrm{N}_{2}$ gas. All experiments were performed in triplicate.

Biogas volume was measured in the flasks by liquid replacement [32] at days 2, 7, and 14 (end of the experiment). This was performed by a gas collection system with an inverted Mariotte bottle filled with saline solution ( $\mathrm{NaCl}$ of $25 \mathrm{~g} \mathrm{~L}^{-1}$ ), which was acidified to $\mathrm{pH} 2.0$ using $\mathrm{H}_{2} \mathrm{SO}_{4}$. The displaced liquid volume corresponded to the volume of produced biogas. Biogas was extracted from the headspace for 
Table 1

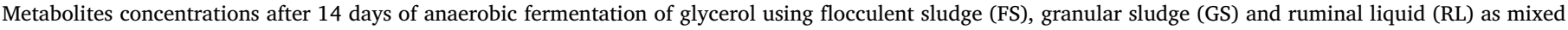
culture and $100 \mathrm{mM}$ of ethanol as electron donor.

\begin{tabular}{|c|c|c|c|c|c|c|c|c|c|}
\hline \multirow[t]{2}{*}{ Mixed culture } & \multirow[t]{2}{*}{ Conditions } & \multicolumn{8}{|c|}{ Metabolites concentrations (g.L ${ }^{-1}$ ) } \\
\hline & & $\mathrm{C} 2$ & $\mathrm{C} 3$ & $\mathrm{C} 4$ & C6 & $\mathrm{C} 8$ & 1,3-PD & Ethanol conversion (\%) & Glycerol conversion (\%) \\
\hline \multirow[t]{3}{*}{ FS } & Control & $0.21^{\mathrm{a}}$ & $0.11^{\mathrm{ac}}$ & ND & $0.12^{\mathrm{e}}$ & $0.42^{\mathrm{a}}$ & ND & - & 99.0 \\
\hline & $+\mathrm{G}$ & $0.20^{\mathrm{a}}$ & $0.50^{\mathrm{b}}$ & $0.72^{\mathrm{a}}$ & ND & ND & $1.07^{\mathrm{a}}$ & - & 99.0 \\
\hline & $+\mathrm{G}+\mathrm{Et}_{100}$ & ND & $0.40^{\mathrm{b}}$ & $0.31^{\mathrm{b}}$ & $1.14^{\mathrm{a}}$ & $0.4^{\mathrm{a}}$ & $0.62^{\mathrm{b}}$ & 85.2 & 99.0 \\
\hline \multirow[t]{3}{*}{ GS } & Control & ND & ND & ND & ND & ND & ND & - & 100.0 \\
\hline & $+\mathrm{G}$ & $0.30^{\mathrm{a}}$ & $0.52^{\mathrm{b}}$ & $0.61^{\mathrm{a}}$ & ND & ND & $0.92^{\mathrm{a}}$ & - & 100.0 \\
\hline & $+\mathrm{G}+\mathrm{Et}_{100}$ & ND & $0.11^{\mathrm{a}}$ & $0.73^{\mathrm{a}}$ & $1.61^{\mathrm{b}}$ & $0.22^{\mathrm{b}}$ & $0.63^{\mathrm{b}}$ & 77.0 & 100.0 \\
\hline \multirow[t]{3}{*}{$\mathrm{RL}$} & Control & ND & $0.21^{\mathrm{c}}$ & ND & $0.40^{\mathrm{c}}$ & ND & ND & - & 100.0 \\
\hline & $+\mathrm{G}$ & $0.21^{\mathrm{a}}$ & $0.33^{\mathrm{cb}}$ & $0.31^{\mathrm{b}}$ & $0.60^{\mathrm{d}}$ & ND & ND & - & 100.0 \\
\hline & $+\mathrm{G}+\mathrm{Et}_{100}$ & $0.21^{\mathrm{a}}$ & $0.11^{\mathrm{ac}}$ & $0.32^{\mathrm{b}}$ & $1.22^{\mathrm{a}}$ & ND & $1.09^{\mathrm{a}}$ & 100.0 & 100.0 \\
\hline
\end{tabular}

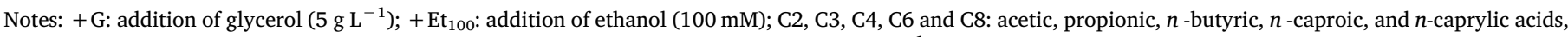

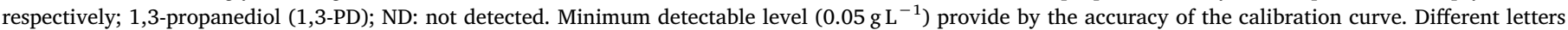
represent significant statistically difference ( $\mathrm{p} \leq 0.05$ ).

determination of $\mathrm{CH}_{4}, \mathrm{H}_{2}$, and $\mathrm{CO}_{2}$ by gas chromatography (C2V-200 micro GC, Thermo Fisher Scientific, Enschede, The Netherlands). The gas chromatograph was equipped with a thermal conductivity detector and a stainless steel capillary column $(10 \mathrm{~m} \times 0.5 \mathrm{~mm})$. The temperatures of the injector, oven, and detector were 120,60 , and $120^{\circ} \mathrm{C}$, respectively. TVS concentrations were measured according to standard methods [33]. At the beginning and at the end of the experiments (after 14 days), aliquots were taken for $\mathrm{pH}$ measurement, and carboxylic acids and alcohol determination by HPLC (Prominence HPLC System 20A, Shimadzu Co., Kyoto, Japan) by using an Aminex HPX-87H column (300 mm $\times 7.8 \mathrm{~mm}$; Bio-Rad Laboratories, CA, USA), refractive index detector (RID-10A, Shimadzu, Kyoto, Japan) at oven temperature of $65^{\circ} \mathrm{C}$; eluent, $5 \mathrm{mM} \mathrm{H}_{2} \mathrm{SO}_{4}$ in MiliQ water; flow rate, $0.6 \mathrm{~mL} \mathrm{~min}^{-1}$.

Statistical significance of differences between treatment groups was evaluated by the one-way analysis of variance (ANOVA) using the Minitab software (version 17.0, Minitab Inc., State College, PA, USA). The significance levels are quoted at the $95 \%$ confidence level $(P \leq 0.05)$.

\subsection{DNA extraction and amplification}

The microbial communities of the bioreactors were characterized as follows. Bacterial genomic DNA was extracted from the inoculum at the beginning and at the end of the batch experiments (day 14) from all bioreactors. Mixed 50-mL liquor samples were taken, centrifuged at $3000 \mathrm{~g}$ for $2 \mathrm{~min}$, and the supernatant was discarded. Nucleic acids were extracted from $0.5 \mathrm{~g}$ of the centrifuged sludge samples by using a PowerSoil DNA Isolation Kit (MO Bio, Carlsbad, CA). DNA concentration and integrity were measured at $260 \mathrm{~nm}$ (NanoDrop 2000 Spectrophotometer, Thermo Scientific, The Netherlands). DNA amplification occurred through the polymerase chain reaction (PCR) for species of both domains, Bacteria and Archaea, with primers containing GC clamps for further analysis by DGGE. For the Archaea domain species, two primers, 0515R-GC (5'-CGC CCG GGG CGC GCC CCG GGC GGG GCG GGG GCA CGG GGG GAT CGT ATT ACC GCG GCT GCT GGC AC-3') and 0109F-T (5'-ACT GCT CAG TAA CAC GT-3'), were used. For the Bacteria domain species, we used primers 1401R (5'-CGG TGT GTA CAA GAC CC-3') and 0968F-GC (5'-CGC CCG GGG CGC GCC CCG GGC GGG GCG GGG GCA CGG GGG GAA CGC GAA GAA CCT TAC-3'). PCR mixtures $(50 \mu \mathrm{L})$ contained $200 \mathrm{mM}$ deoxynucleoside triphosphate, $1.5 \mathrm{mM} \mathrm{MgCl} 2$, primers at a $0.2 \mathrm{mM}$ concentration each, $1.25 \mathrm{U}$ of GoTaqDNA polymerase (Promega, Madison, WI, USA), 1 or $2 \mu \mathrm{L}$ of the DNA template, and Milli-Q water to complete the volume. The PCR colorless buffer was supplied with the enzyme. The fragments were amplified using the following program: Bacteria domain $-95^{\circ} \mathrm{C}$ for 2 min, 31 cycles of $95^{\circ} \mathrm{C}$ for $30 \mathrm{~s}, 58^{\circ} \mathrm{C}$ for $45 \mathrm{~s}, 72{ }^{\circ} \mathrm{C}$ for $60 \mathrm{~s}$, and $72{ }^{\circ} \mathrm{C}$ for $6 \mathrm{~min}$; Archaea domain $-95^{\circ} \mathrm{C}$ for $2 \mathrm{~min}, 31$ cycles of $95^{\circ} \mathrm{C}$ for $30 \mathrm{~s}$,
$52{ }^{\circ} \mathrm{C}$ for $40 \mathrm{~s}, 72{ }^{\circ} \mathrm{C}$ for $90 \mathrm{~s}$, and $72{ }^{\circ} \mathrm{C}$ for $6 \mathrm{~min}$. The sizes of PCR products were estimated with the DNA marker of 2000 base pairs Hypperladder II (Bioline, USA Inc.) in agarose gel electrophoresis $(1.8 \%)$ after staining with SYBR Safe DNA gel (Invitrogen, Cergy Pontoise, France). All primers were synthesized commercially by IDT Integrated DNA Technologies (Iowa, USA). Bacterial amplicons were subsequently separated by denaturing gradient gel electrophoresis (DGGE) using a denaturant gradient ranging from $57 \%$ to $72 \%$.

\subsection{DGGE and analysis of the fingerprints}

A Bio-Rad DCode ${ }^{\mathrm{TM}}$ Universal Mutation Detection System (Bio Rad Laboratories Inc., Hercules, CA, USA) was used for running $8 \%(\mathrm{w} / \mathrm{v})$ polyacrylamide DGGE gels with a denaturing gradient ranging from $57 \%$ to $72 \%$. Electrophoresis was conducted in the $1 \times$ TAE (Tris/acetic acid/EDTA) buffer solution at $60{ }^{\circ} \mathrm{C}$ for $16 \mathrm{~h}$ and at $85 \mathrm{~V}$ for the PCR product with bacterial primers. For the archaeal PCR products, the conditions were slightly different: $60^{\circ} \mathrm{C}, 18 \mathrm{~h}$, and $65 \mathrm{~V}$, respectively. Gels were stained with the SYBR Green I dye (Sigma-Aldrich, St. Louis, MO, USA) for $1 \mathrm{~h}$ and subsequently displayed in a UV transilluminator (Bio Rad Laboratories Inc., Hercules, CA, USA). DGGE profiles were aligned and analyzed with the Gel Compar II software (Applied Maths, Sint-Martens-Latem, Belgium) to obtain the matrix of relative band intensity values according to the band positions. DGGE dendrograms were constructed and the similarity coefficient was calculated using the Jaccard correlation [34].

\section{Results and discussion}

\subsection{Glycerol fermentation by an open culture}

Tests were performed to investigate the production of metabolites with different seed inocula and glycerol as the main source of carbon and energy. The use of mixed culture was chosen due its advantages according to Spirito and co-authors [18]. Table 1 shows concentrations of metabolites that were synthesized after 14 days of glycerol fermentation using FS, GS, and RL as inocula with $100 \mathrm{mM}$ of ethanol as the electron donor to produce MCCA via the chain elongation metabolic pathway [19].

$\mathrm{RL}$ was the only inoculum able to produce $n$-caproic acid from glycerol as the sole source of carbon and energy $\left(0.6 \mathrm{~g} \mathrm{~L}^{-1}\right)$. The microbial community present in RL is naturally able to produce $n$-caproic acid [35]. According to the later authors, organisms such as Eubacterium pyruvativorans, which is a non-saccharolytic amino acid-fermenting anaerobe from the rumen, are able to synthesize $n$-caproic acid as the main fermentation product, and they have metabolic properties analogous to those of $C$. kluyveri. C. kluyveri organism has been reported as 
Table 2

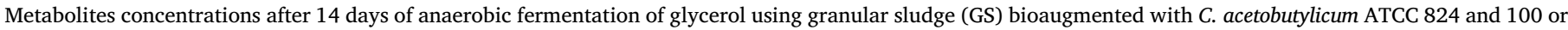
$200 \mathrm{mM}$ of ethanol as electron donor.

\begin{tabular}{|c|c|c|c|c|c|c|c|c|}
\hline \multirow[t]{2}{*}{ Conditions } & \multicolumn{8}{|c|}{ Metabolites concentrations (g.L ${ }^{-1}$ ) } \\
\hline & $\mathrm{C} 2$ & $\mathrm{C} 3$ & $\mathrm{C} 4$ & C6 & $\mathrm{C} 8$ & 1,3-PD & Ethanol conversion (\%) & Glycerol conversion (\%) \\
\hline$+\mathrm{G}+\mathrm{Et}_{100}+\mathrm{C} . \mathrm{a}$ & ND & $0.41^{\mathrm{a}}$ & $0.52^{\mathrm{a}}$ & $3.82^{\mathrm{a}}$ & 1.72 & $2.02^{\mathrm{a}}$ & 57 & 100.0 \\
\hline$+\mathrm{G}+\mathrm{Et}_{200}+\mathrm{C} . \mathrm{a}$ & 0.21 & $0.50^{\mathrm{a}}$ & $2.31^{\mathrm{b}}$ & $3.84^{\mathrm{a}}$ & ND & $1.62^{\mathrm{b}}$ & 50.9 & 100.0 \\
\hline
\end{tabular}

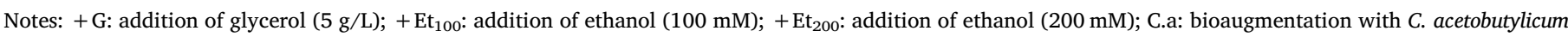

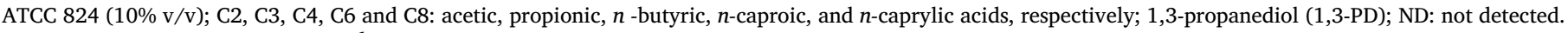
Minimum detectable level $\left(0.05 \mathrm{~g} \mathrm{~L}^{-1}\right)$ provide by the accuracy of the calibration curve. Different letters represent significant statistically difference ( $\left.\mathrm{p} \leq 0.05\right)$.

one of the few isolate species with the ability to produce $n$-caproic acid $[28,37]$. However, if one takes into account that the control flask produced $0.4 \mathrm{~g} \mathrm{~L}^{-1} n$-caproic acid without addition of glycerol or ethanol, it can be assumed that the net production of $n$-caproic acid from glycerol is very low $\left(0.2 \mathrm{~g} \mathrm{~L}^{-1}\right)$.

Formation of $n$-caproic acid has been postulated as secondary fermentation in hydrogen production [28]. According to Ding and coauthors [28], during the process of anaerobic fermentation, when methanogens are strongly inhibited, hydrogenogenic acidogens convert carbohydrates to $\mathrm{H}_{2}$, short-chain carboxylic acids (with the carbon number less than 5), and alcohols [28]. Saccharolytic Clostridia tend to facilitate alcohol production via solventogenesis in mildly acidic conditions, resulting in low production of hydrogen and $n$-caproic acid. Kenealy and collaborators [14], using co-cultures of C. kluyveri and cellulolytic rumen species, reported $n$-caproic acid accumulation of $4.6 \mathrm{~g} \mathrm{~L}^{-1}$ from ethanol and cellulose. Steinbusch and co-authors [16] showed that mixed microbial communities in fed-batch reactors were able to produce $n$-caproic acid and $n$-caprylic acid at concentrations of $8.17 \mathrm{~g} \mathrm{~L}^{-1}$ and $0.32 \mathrm{~g} \mathrm{~L}^{-1}$, respectively, from acetic acid. Grootscholten and co-authors [37] reported even higher $n$-caproic acid and $n$-caprylic concentration of $11.1 \mathrm{~g} \mathrm{~L}^{-1}$ and $0.9 \mathrm{~g} \mathrm{~L}^{-1}$, respectively, in an elongation reaction in the presence of acetic acid and ethanol, using an upflow anaerobic filter.

It is well known that glycerol is a natural substrate for 1,3-PD production [38] and the latter was observed by us with all three inocula tested. In the reductive pathway, glycerol is first converted to 3-hydroxypropionaldehyde in a enzymatic reaction catalyzed by vitamin $\mathrm{B}_{12}$ and then, the aldehyde is reduced to 1,3-PD [38]. The highest production of carboxylic acids, mainly $n$-caproic acid, was obtained with GS (1.6 g L ${ }^{-1}$ of $n$-caproic acid), and only traces of $n$-caprylic acid were formed. Similar results were found in another study [19] that reported production of $2.8 \mathrm{~g} \mathrm{~L}^{-1}$ of $n$-caproic acid during acidification of municipal solid waste by ethanol addition. The authors observed a lag phase of 2 days before $n$-caproic acid formation, while the ethanol concentration decreased.

Chloroform proved to be a very efficient inhibitor of methanogenic activity, because no methane was detected in the biogas produced. Ning and collaborators [31] demonstrated that a chemical treatment with $0.05 \%$ chloroform was able to selectively inhibit methanogens, because coenzyme $\mathrm{M}$ reductase was inhibited [39]. In all batch tests, the main components of the biogas were $\mathrm{H}_{2}$ and $\mathrm{CO}_{2}$. The methanogenic population was almost completely inactivated, and only an insignificant amount of $\mathrm{CH}_{4}$ was detected (equivalent to $0.1-0.2 \%$ of the COD recovered), indicating that chemical treatment applied to sludge was successful.

\subsection{Bioaugmentation with C. acetobutylicum}

Since GS achieved the highest concentration of $n$-caproic acid among all three seed inocula tested, it was used for the bioaugmentation assays. In addition, the concentration of ethanol was increased to $200 \mathrm{mM}$ in an attempt to enhance $n$-caproic acid production. $C$. acetobutylicum ATCC 824 was chosen due to its ability to grow on a variety of carbohydrates, making fermentation of many agricultural, industrial, and waste products possible [40,41]. For example, during fermentation of several sugars (glucose, mannose, arabinose, and xylose) by solventogenic Clostridia, including C. acetobutylicum ATCC 824, the main products obtained were $n$-butanol, acetone, and ethanol [40]. During the exponential growth, $C$. acetobutylicum converts sugars to acetic acid and $n$-butyric acid along with molecular hydrogen to generate energy in addition to the glycolytic ATP [42]. At pH 6.0, only one growth phase occurs, and only acids are formed [43]. Indeed, in our previous work [44], we observed that at $\mathrm{pH}$ range of 5.5-6.5, the main products formed during glycerol fermentation were acetic and $n$-butyric acid.

In the oxidative pathway during glycerol fermentation by Clostridium species, such as C. butyricum [21] and C. pasteurianum [8], glycerol is converted to formic acid, ethanol, $n$-butyric acid, and acetic acid through pyruvate [45]. It has been shown that $n$-caproic acid can be synthesized from ethanol and acetic acid, or from ethanol and $n$ butyric [28]. According to Grootscholten and co-authors [37], formation of $n$-caproic acid from ethanol requires $n$-butyric acid that can be indirectly synthesized from acetic acid and ethanol. Thus, by adding $C$. acetobutylicum ATCC 824 to a mixed culture containing glycerol, we sought to enhance $n$-caproic acid production. Indeed, this strain is able to produce acetic, butyric acid, and ethanol, depending on the nutritional conditions [46]. This is because it contains $n$-butyric acid kinase with highly specific activity [47] that catalyzes reversible formation of $n$-butyric acid from butyryl phosphate with concomitant phosphorylation of ADP [48]. However, the mechanism involving CoA transferase in $n$-butyric acid formation differs from that in C. kluyveri. The enzymes phosphotransbutyrylase and $n$-butyric acid kinase are involved in the production of $n$-butyric acid from butyryl-CoA by $C$. acetobutylicum ATCC $824[48,49]$.

Table 2 shows the results of the bioaugmentation experiment with C. acetobutylicum ATCC 824 when GS was used as inoculum, and 100-200 mM ethanol was added as electron donor. In the presence of $100 \mathrm{mM}$ ethanol, higher concentration of $n$-caproic and $n$-caprylic acids were observed with bioaugmentation than without it. In this condition ( $100 \mathrm{mM}$ ethanol), chain elongation proceeded and $n$-caprylic acid was obtained at a concentration of $1.7 \mathrm{~g} \mathrm{~L}^{-1}$. Bioaugmentation is a complex phenomenon that involves different metabolic pathways in multiple species of microorganisms acting in synergism. For each biological process involving bioaugmentation, different metabolic pathways are engaged at various interactions. In this study, bioaugmentation enhanced production of $n$-caproic and $n$-caprylic acids. The higher concentration were probably due to better utilization of the substrate by mixed cultures. It is important to highlight that no $n$-caproic acid was detected in the inoculum culture medium, in which no substrate was added.

Microbial communities present in granular sludge have been previously demonstrated to produce acetic acid and $n$-butyric acid [50]. Therefore, it is possible that $C$. acetobutylicum ATCC 824 (present in the GS) promoted biosynthesis of $n$-caproic and caprylic acids by producing $n$-butyric acid. In our previous studies [44], we observed that $C$. acetobutylicum ATCC 824, when it was grown in pure culture with glycerol, produced $n$-butyric acid, however no production of $n$-caproic or $n$ - 


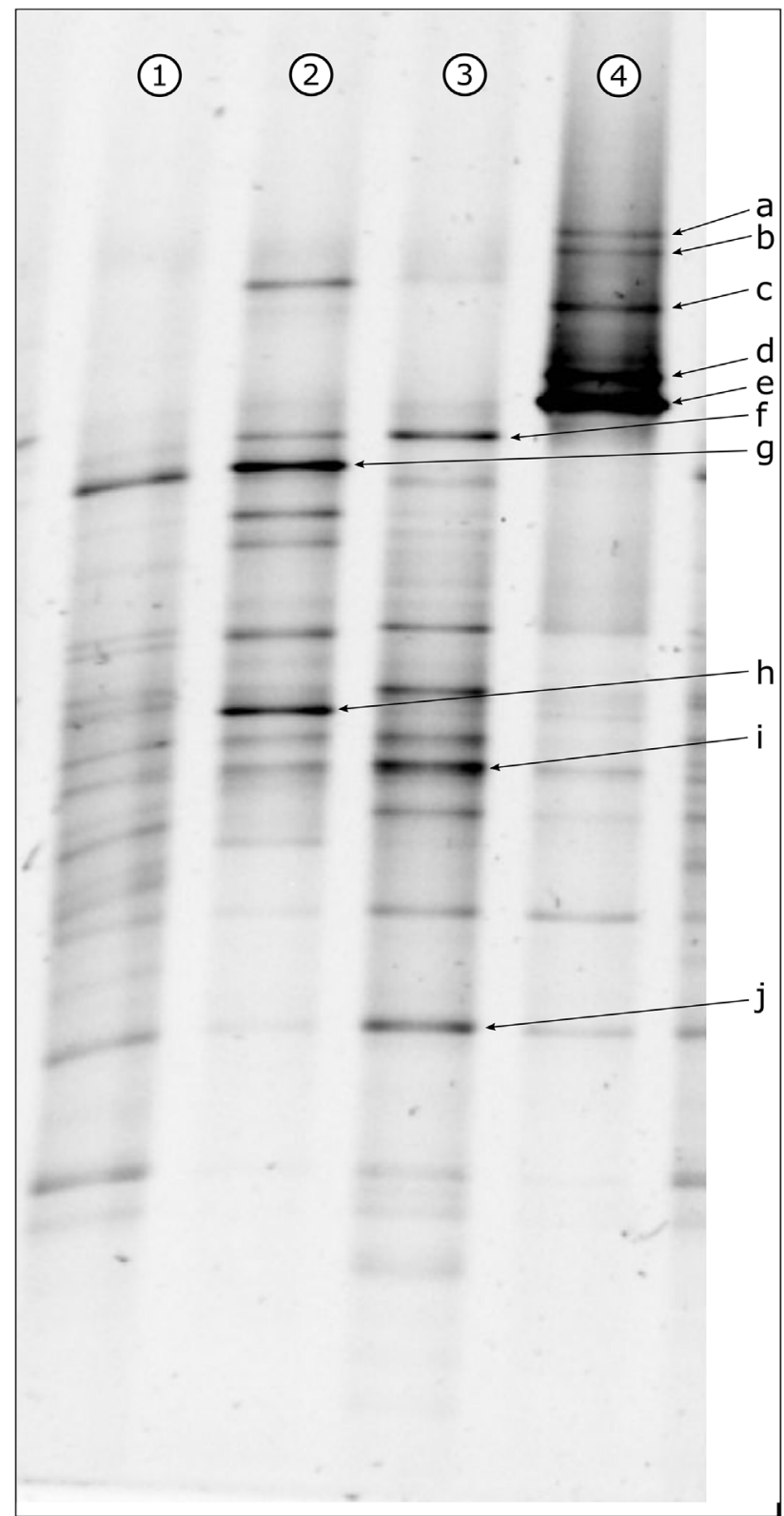

Fig. 1. DGGE profiles of sludge samples: (1) seed sludge sample (granular); (2) seed sludge plus glycerol $\left(5 \mathrm{~g} \mathrm{~L}^{-1}\right)$; (3) seed sludge plus glycerol $\left(5 \mathrm{~g} \mathrm{~L}^{-1}\right)$ plus $100 \mathrm{mM}$ of ethanol; (4) seed sludge plus glycerol $\left(5 \mathrm{~g} \mathrm{~L}^{-1}\right)$ plus $100 \mathrm{mM}$ of ethanol plus Clostridium acetobutylicum ATCC 0824 (10\% v/v).

caprylic acid was observed. Furthermore, it is also possible that other strains naturally present in GS have contributed to increased production of these carboxylic acids. As already demonstrated by Steinbusch et al. [16] and Agler et al. [17], species related to C. kluyveri dominated the microbial community during the formation of $n$-caproic acid and $n$ caprylic acid in fed-batch reactors.

When GS was amended with $C$. acetobutylicum, augmentation resulted in a beneficial enrichment of the community and, as a result, increased production of the carboxylic acids and 1,3-PD. However, other members of the bacterial community may also play important roles during fermentation, e.g., granulation enhancers, redox-maintainers, or hydrolyzers of complex materials [51]. Our results indicated that it is possible to improve production of carboxylic acids, such as $n$ caproic acid, by bioaugmentation during batch fermentation. Furthermore, it indicates that bioaugmentation can contribute to improved reactor performance in practical circumstances. Indeed, it has been shown that bioaugmented pure culture of Clostridium butyricum, remained active during a continuous period of non-sterile conditions when hydrogen was produced from sugarcane juice in a non-sterile stirred tank reactor [52]. Similar findings were reported by Weimer et al. [36], who observed significantly higher production of $n$-caproic and $n$-caprylic acids in conditions when an open ruminal culture was augmented with $C$. kluyveri, and when cellulosic biomass (alfalfa stems) and ethanol were used as substrate and electron donor, respectively.

In our experiments, surprisingly, there was no production of $n$ caprylic acid, when the concentration of ethanol was increased to $200 \mathrm{mM}$, and accumulation of $n$-butyric acid and ethanol was observed (Table 2). There could be several reasons why chain elongation did not proceed in this condition: i) toxicity caused by the excess of metabolites from the primary glycerol fermentation $[53,54]$; ii) toxicity of $n$-caproic acid itself, because the concentration obtained $\left(3.8 \mathrm{~g} \mathrm{~L}^{-1}\right)$ were much higher than the levels considered toxic $\left(800-870 \mathrm{mg} \mathrm{L}^{-1}\right)$ under long operating periods [38,56], especially at low $\mathrm{pH}[14]$. According to Steinbusch et al. [16], carboxylic acids production is $\mathrm{pH}$-dependent. These authors reported no $n$-caprylic acid production in reactors at $\mathrm{pH}$ 5.5. At pH 5.5, the toxic chemical species are the unionized $n$-caproic and $n$-caprylic acids, because $\mathrm{pH} 5.5$ is close to their $\mathrm{pK}_{\mathrm{a}}$ (4.88) [17]. In our setting, batch experiments were conducted for short periods (14 days) and at the end of those periods, $\mathrm{pH}$ remained at $\sim 6.5$ in the presence of $100 \mathrm{mM}$ ethanol, allowing chain elongation to occur. In contrast, at the higher ethanol concentration $(200 \mathrm{mM}), \mathrm{pH}$ dropped to $\sim 4.5$ and no $n$-caprylic acid was produced. In other studies, chain elongation did occur at a lower $\mathrm{pH}$ of 5.5, but the MCCAs were extracted from the fermentation broth to prevent product toxicity $[17,56]$.

\subsection{DGGE analysis}

In this study, we used DGGE to determine the diversity of bacteria present in the bioaugmented sludge (GS) without further characterization of the individual species. This technique is based on the assumption that sequences will migrate to different positions in DGGE gels $[55,57]$, and it has been used in several environments to investigate the microbial diversity in biological reactors [58-61]. Although simulations have demonstrated that $95 \%$ of single base sequence differences should be detected by this method [60], limitations have been observed, and some studies have reported difficulty in separating different $16 \mathrm{~S}$ rDNA sequences by DGGE. For example, Jackson and Churchill [61] observed that two sequences that differed by 2 base pairs showed identical migration in DGGE gels and could not be separated in a mixed sample. However, here we used a denaturing gradient range of $57-72 \%$, which was narrower than the range commonly used in other studies, e.g., $30-60 \%[58,62,63,64,65]$ or $40-60 \%$ [34]. The use of the smaller gradient enabled separation of similarly migrating sequences, therefore mitigating possible limitations of DGGE. Other studies also utilized a smaller gradient with environmental samples. For example, for evaluation of microbial diversity during hydrogen production by anaerobic sludge [31], and for functional studies of ammonia-oxidizing bacterial communities in sequential batch reactors [64].

Shannon Richness indexes ( $R r)$ of the bacterial community were calculated based on the total number of bands by the percentage of the denaturing gradient needed to describe the total diversity [65]. Diversity has been defined as a function of two components: i) the total number of species present, known as richness or species abundance; and ii) the distribution of individuals among those species, known as species evenness or equitability [66]. Bacterial PCR-DGGE profiles with and without bioaugmentation is shown in Fig. 1. The results showed that the community composition of the GS shifted, and differences in the number and pattern between communities were observed. At least 20 detectable DGGE bands were observed (Lane 1) and showed a medium richness $(\mathrm{Rr}=16)$. When glycerol (Lane 2) or ethanol (Lane 3) was 
added, intensity of some bands became higher (e.g., for bands $f, g, h, i$, and $j$ ). However, bacterial diversity remained almost the same compared to the seed sludge (Lane 1). When the sludge was amended with C. acetobutylicum (Lane 5), a new dominant population appeared, whereas bands $a, b, c, d$, and $e$, as well as richness parameter, became smaller $(\mathrm{Rr}<10)$.

According to Marzorati and co-authors [65], functional organization (Fo) can be defined as the ability of the community to organize into an adequate distribution of dominant microorganisms and resilient ones. It is the result of the activity of those microorganisms that are most fitting to the ongoing environmental-microbiological interactions and that become dominant within the structure of the microbial community. Following the method described by Marzorati and co-authors, Fo of the bacterial communities were based on Pareto-Lorenz (PL) evenness curves. For each DGGE lane, the respective bands are ranked from high to low, based on their intensities: 25\% PL curves represent a low functional organization, while $80 \%$ PL curves indicate a specialized community and highly organized.

The results of our experiments indicate that the communities present in all treatments achieved a good Fo and stability in terms of the species composition. Furthermore, different treatments applied to the experimental phases of the bioreactors exerted a selective pressure on the microbial community. In this scenario, the community can potentially adapt to changing environmental conditions and preserve its functionality [65]. In the bioaugmented sludge, there were at least six detectable DGGE bands (Fig. 1, Lane 4). DGGE community fingerprinting showed that bands $a, b, c, d$, and $e$ (Lane 4) have become dominant, and this circumstance might be related to the improvement of carboxylic acids production (Table 2). These results suggest that the bacterial community strengthened with bioaugmentation and became predominantly composed of microorganisms resistant to adverse environment, such as acidic conditions, observed at the end of the experiments ( $\mathrm{pH} 4.0$ ). Similar studies were done by others authors to a better understanding of the metabolic production by microbial community knowledge. Kim et al. [67] found that $C$. acetobutylicum was the dominant species during $\mathrm{H}_{2}$ fermentation of food waste in a specific $\mathrm{pH}$ condition ( $\mathrm{pH}$ range 1.0-3.0). Reddy et al. [68], when studying a bioprocess for conversion of ethanol and SCCA into MCCA using enriched mixed culture with C. kluyveri observed predominantly Clostridia, Sphingobacteriales, Desulfobacteraceae and Bacillus groups in the bioaugmented mixed culture. Leng and co-authors [69] reported thermodynamic and physiological insights for co-production of 1,3-PD and $n$-caproic acid from glycerol and acetic acid. According to the DGGE analysis the co-production system is a resulting of co-existence of Clostridium butyricum, Escherichia coli, Clostridium kluyveri and some other butyrate production bacteria.

\section{Conclusions}

The main novelty of this work was the use of the strain $C$. acetobutylicum ATCC 824 to increase the MCCA, mainly $n$-caproic acid, production through bioaugmentation. We revealed that a combination of metabolic pathways of all members of the microbial community can improve the efficiency of the anaerobic fermentation. Our results indicated that the production rates of carboxylic acids and alcohols were higher in the presence of bioaugmentation than in its absence. To become part of a successful bioaugmentation supplement, the added organisms need to be able to grow, remain metabolically active, and show some dominance over the microbial community already resident in the environment. However, the exact mechanism of the bioaugmentation process is complex and not completely elucidated. Addition of active microbial cells directly to the pre-existing bacterial community resulted in an enhancement of carboxylic acids production during glycerol fermentation via the chain elongation process.

\section{Acknowledgments}

This work was supported by the Brazilian Agricultural Research Corporation (Embrapa) under Call 11/2012-Macroprograma 3; the Brazilian National Council for Research and Technology (CNPq) under Grant 401394/2014-0 and 472420/2013-5; and the Ceará State Foundation for the Support of Scientific and Technological Development (FUNCAP) under Grant no. 350365/2013-0 and DCR 002400477.02.00/12.

\section{References}

[1] Y.C. Lo, X.J. Chen, C.Y. Huang, Y.J. Yuan, J.S. Chang, Dark fermentative hydrogen production with crude glycerol from biodiesel industry using indigenous hydrogenproducing bacteria, Int. J. Hydrogen Energy 38 (2013) 15815-15822, https://doi. org/10.1016/j.ijhydene.2013.05.083.

[2] F. Yang, M.A. Hanna, R. Sun, Value-added uses for crude glycerol - a byproduct of biodiesel production, Biotechnol. Biofuels 5 (2012) 13, https://doi.org/10.1186/ 1754-6834-5-13.

[3] OECD-FAO, Biofuels, OECD-FAO Agric. Outlook, OECD Publishing, Paris, 2015, p. 144, , https://doi.org/10.1787/agr_outlook-2015-13-en.

[4] Z.X. Wang, J. Zhuge, H. Fang, B.A. Prior, Glycerol production by microbial fermentation: a review, Biotechnol. Adv. 19 (2001) 201-223, https://doi.org/10. 1016/S0734-9750(01)00060-X.

[5] Q.M. Viana, M.B. Viana, E.A.F. Vasconcelos, S.T. Santaella, R.C. Leitão, Fermentative H2 production from residual glycerol: a review, Biotechnol. Lett. 36 (2014) 1381-1390, https://doi.org/10.1007/s10529-014-1507-4.

[6] M.S. Fountoulakis, T. Manios, Enhanced methane and hydrogen production from municipal solid waste and agro-industrial by-products co-digested with crude glycerol, Bioresour. Technol. 100 (2009) 3043-3047, https://doi.org/10.1016/j. biortech.2009.01.016.

[7] B.R. Oh, J.W. Seo, S.Y. Heo, W.K. Hong, L.H. Luo, M. ho Joe, D.H. Park, C.H. Kim, Efficient production of ethanol from crude glycerol by a Klebsiella pneumoniae mutant strain, Bioresour. Technol. 102 (2011) 3918-3922, https://doi.org/10. 1016/j.biortech.2010.12.007.

[8] C. Moon, C. Hwan Lee, B.I. Sang, Y. Um, Optimization of medium compositions favoring butanol and 1,3-propanediol production from glycerol by Clostridium pasteurianum, Bioresour. Technol. 102 (2011) 10561-10568, https://doi.org/10. 1016/j.biortech.2011.08.094.

[9] Z.G. Li, Y.Q. Sun, W.L. Zheng, H. Teng, Z.L. Xiu, A novel and environment-friendly bioprocess of 1,3-propanediol fermentation integrated with aqueous two-phase extraction by ethanol/sodium carbonate system, Biochem. Eng. J. 80 (2013) 68-75, https://doi.org/10.1016/j.bej.2013.09.014.

[10] L. MacIs, R. Daniel, G. Gottschalk, Properties and sequence of the coenzyme B12dependent glycerol dehydratase of Clostridium pasteurianum, FEMS Microbiol. Lett. 164 (1998) 21-28, https://doi.org/10.1016/S0378-1097(98)00186-4.

[11] M.F. Temudo, R. Poldermans, R. Kleerebezem, M.C.M. Van Loosdrecht, Glycerol fermentation by (open) mixed cultures: a chemostat study, Biotechnol. Bioeng. 100 (2008) 1088-1098, https://doi.org/10.1002/bit.21857.

[12] L.T. Angenent, H. Richter, W. Buckel, C.M. Spirito, K.J.J. Steinbusch, C.M. Plugge, D.P.B.T. Strik, T.I.M. Grootscholten, C.J.N. Buisman, H.V.M. Hamelers, Chain elongation with reactor microbiomes: open-culture biotechnology to produce biochemicals, Environ. Sci. Technol. 50 (2016) 2796-2810, https://doi.org/10.1021/ acs.est.5b04847.

[13] M. Verser, D.W. Park, Method for the Indirect Production of Butanol and Hexanol, (2012) US8252567.

[14] W.R. Kenealy, Y. Cao, P.J. Weimer, Production of caproic acid by cocultures of ruminal cellulolytic bacteria and Clostridium kluyveri grown on cellulose and ethanol, Appl. Microbiol. Biotechnol. 44 (1995) 507-513, https://doi.org/10.1007/ s002530050590.

[15] F. Boyen, F. Haesebrouck, A. Vanparys, J. Volf, M. Mahu, F. Van Immerseel, I. Rychlik, J. Dewulf, R. Ducatelle, F. Pasmans, Coated fatty acids alter virulence properties of Salmonella Typhimurium and decrease intestinal colonization of pigs, Vet. Microbiol. 132 (2008) 319-327, https://doi.org/10.1016/j.vetmic.2008.05. 008.

[16] K.J.J. Steinbusch, H.V.M. Hamelers, C.M. Plugge, C.J.N. Buisman, Biological formation of caproate and caprylate from acetate: fuel and chemical production from low grade biomass, Energy Environ. Sci. 4 (2011) 216, https://doi.org/10.1039/ c0ee00282h.

[17] M.T. Agler, C.M. Spirito, J.G. Usack, J.J. Werner, L.T. Angenent, Chain elongation with reactor microbiomes: upgrading dilute ethanol to medium-chain carboxylates, Energy Environ. Sci. 5 (2012) 8189, https://doi.org/10.1039/c2ee22101b.

[18] C.M. Spirito, H. Richter, K. Rabaey, A.J.M. Stams, L.T. Angenent, Chain elongation in anaerobic reactor microbiomes to recover resources from waste, Curr. Opin. Biotechnol. 27 (2014) 115-122, https://doi.org/10.1016/j.copbio.2014.01.003.

[19] T.I.M. Grootscholten, F.K. dal Borgo, H.V.M. Hamelers, C.J.N. Buisman, Promoting chain elongation in mixed culture acidification reactors by addition of ethanol, Biomass Bioenergy 48 (2013) 10-16, https://doi.org/10.1016/j.biombioe.2012.11. 019.

[20] M.T. Agler, B.A. Wrenn, S.H. Zinder, L.T. Angenent, Waste to bioproduct conversion with undefined mixed cultures: the carboxylate platform, Trends Biotechnol. 29 (2011) 70-78, https://doi.org/10.1016/j.tibtech.2010.11.006.

[21] A.-P. Zeng, Pathway and kinetic analysis of 1, 3-propanediol production from glycerol fermentation by Clostridium butyricum L-ATP, Bioprocess Eng. 14 (1996) 169-175.

[22] A.K. Forrest, R. Sierra, M.T. Holtzapple, Effect of biodiesel glycerol type and 
fermentor configuration on mixed-acid fermentations, Bioresour. Technol. 101 (2010) 9185-9189, https://doi.org/10.1016/j.biortech.2010.07.041.

[23] T. Ito, Y. Nakashimada, K. Senba, T. Matsui, N. Nishio, Hydrogen and ethanol production from glycerol-containing wastes discharged after biodiesel manufacturing process, J. Biosci. Bioeng. 100 (2005) 260-265, https://doi.org/10.1263/ jbb.100.260.

[24] R.J. Wallace, L.C. Chaudhary, E. Miyagawa, N. McKain, N.D. Walker, Metabolic properties of Eubacterium pyruvativorans, a ruminal "hyper-ammonia-producing" anaerobe with metabolic properties analogous to those of Clostridium kluyveri, Microbiology 150 (2004) 2921-2930, https://doi.org/10.1099/mic.0.27190-0.

[25] M. Marounek, K. Fliegrova, S. Bartos, Metabolism and some characteristics of ruminal strains of Megasphaera elsdenii, Appl. Environ. Microbiol. 55 (1989) 1570-1573.

[26] B.S. Jeon, B.C. Kim, Y. Um, B.I. Sang, Production of hexanoic acid from d-galactitol by a newly isolated Clostridium sp. BS-1, Appl. Microbiol. Biotechnol. 88 (2010) 1161-1167, https://doi.org/10.1007/s00253-010-2827-5.

[27] H.A. Barker, M. Taha, Clostridium Kluyverii, an organism concerned in the for mation of caproic acid from ethyl alcohol, J. Bacteriol. 43 (1941) 347-363.

[28] H.B. Ding, G.Y.A. Tan, J.Y. Wang, Caproate formation in mixed-culture fermentative hydrogen production, Bioresour. Technol. 101 (2010) 9550-9559, https://doi. org /10.1016/j. biortech.2010.07.056.

[29] V.P. Tale, J.S. Maki, D.H. Zitomer, Bioaugmentation of overloaded anaerobic digesters restores function and archaeal community, Water Res. 70 (2015) 138-147, https://doi.org/10.1016/j.watres.2014.11.037.

[30] G. Kumar, P. Bakonyi, P. Sivagurunathan, S.H. Kim, N. Nemestóthy, K. Bélafi-Bakó, C.Y. Lin, Enhanced biohydrogen production from beverage industrial wastewater using external nitrogen sources and bioaugmentation with facultative anaerobic strains, J. Biosci. Bioeng. 120 (2015) 155-160, https://doi.org/10.1016/j.jbiosc. 2014.12.011.

[31] Y.Y. Ning, D.W. Jin, G.P. Sheng, H. Harada, X.Y. Shi, Evaluation of the stability of hydrogen production and microbial diversity by anaerobic sludge with chloroform treatment, Renew. Energy 38 (2012) 253-257, https://doi.org/10.1016/j.renene. 2011.07.038.

[32] M. Soto, R. Mendèz, J.M. Lema, Methanogenic and non-metanogenic activity tests: theoretical basis and experimental setup, Water Res. 27 (1993) 1361-1376.

[33] APHA, Standard Methods for the Examination of Water and Wastewaters, twentyfirst ed., (2012)

[34] C.Z. Lazaro, V. Perna, C. Etchebehere, M.B.A. Varesche, Sugarcane vinasse as substrate for fermentative hydrogen production: the effects of temperature and substrate concentration, Int. J. Hydrogen Energy 39 (2014) 6407-6418, https://doi. org/10.1016/j.ijhydene.2014.02.058.

[35] R.J. Wallace, N. McKain, N.R. McEwan, E. Miyagawa, L.C. Chaudhary, T.P. King, N.D. Walker, J.H.A. Apajalahti, C.J. Newbold, Eubacterium pyruvativorans sp. nov., a novel non-saccharolytic anaerobe from the rumen that ferments pyruvate and amino acids, forms caproate and utilizes acetate and propionate, Int. J. Syst. Evol. Microbiol. 53 (2003) 965-970, https://doi.org/10.1099/ijs.0.02110-0.

[36] P.J. Weimer, M. Nerdahl, D.J. Brandl, Production of medium-chain volatile fatty acids by mixed ruminal microorganisms is enhanced by ethanol in co-culture with Clostridium kluyveri, Bioresour. Technol. 175 (2015) 97-101, https://doi.org/10. 1016/j.biortech.2014.10.054

[37] T.I.M. Grootscholten, K.J.J. Steinbusch, H.V.M. Hamelers, C.J.N. Buisman, Chain elongation of acetate and ethanol in an upflow anaerobic filter for high rate MCFA production, Bioresour. Technol. 135 (2013) 440-445, https://doi.org/10.1016/j. biortech.2012.10.165.

[38] H. Biebl, K. Menzel, A.P. Zeng, W.D. Deckwer, Microbial production of 1,3-propanediol, Appl. Microbiol. Biotechnol. 52 (1999) 289-297, https://doi.org/10.1007/ s002530051523.

[39] R.S. Oremland, D.G. Capone, Use of specific inhibitors in biogeochemistry and microbial ecology, Adv. Microb. Ecol. 10 (1988) 285-383 https://doi.org/10.1007/ 978-1-4684-5409-3 8.

[40] T. Ezeji, H.P. Blaschek, Fermentation of dried distillers' grains and solubles (DDGS) hydrolysates to solvents and value-added products by solventogenic clostridia, Bioresour. Technol. 99 (2008) 5232-5242, https://doi.org/10.1016/j.biortech. 2007.09.032.

[41] N. Qureshi, X.L. Li, S. Hughes, B.C. Saha, M.A. Cotta, Butanol production from corn fiber xylan using Clostridium acetobutylicum, Biotechnol. Prog. 22 (2006) 673-680, https://doi.org/10.1021/bp050360w.

[42] D. Lehmann, T. Lütke-Eversloh, Switching Clostridium acetobutylicum to an ethanol producer by disruption of the butyrate/butanol fermentative pathway, Metab. Eng. 13 (2011) 464-473, https://doi.org/10.1016/j.ymben.2011.04.006.

[43] F. Monot, J.M. Engasser, H. Petitdemange, Influence of $\mathrm{pH}$ and undissociated butyric acid on the production of acetone and butanol in batch cultures of Clostridium acetobutylicum, Appl. Microbiol. Biotechnol. 19 (1984) 422-426, https://doi.org/ 10.1007/BF00454381.

[44] R.I. Dams, A.A. Guilherme, M.S. Vale, V.F. Nunes, R.C. Leitão, S.T. Santaella, Fermentation of residual glycerol by Clostridium acetobutylicum ATCC 824 in pure and mixed cultures, Environ. Technol. 3330 (2016) 1-9, https://doi.org/10.1080/ 09593330.2016.1173114.

[45] P. Kubiak, K. Leja, K. Myszka, E. Celińska, M. Spychała, D. SzymanowskaPowałowska, K. Czaczyk, W. Grajek, Physiological predisposition of various Clostridium species to synthetize 1,3-propanediol from glycerol, Process Biochem. 47 (2012) 1308-1319, https://doi.org/10.1016/j.procbio.2012.05.012.

[46] L. GIRBAL, C. CROUX, I. VASCONCELOS, P. SOUCAILLE, Regulation of metabolic shifts in Clostridium-Acetobutylicum Atcc-824, FEMS Microbiol. Rev. 17 (1995) 287-297, https://doi.org/10.1111/j.1574-6976.1995.tb00212.x.

[47] M.G.N. Hartmanis, S. Gatenbeck, Intermediary Metabolism in Clostridium Acetobutylicum: Levels of Enzymes Involved in the Formation of Acetate and
Butyrate Intermediary Metabolism in Clostridium Acetobutylicum: Levels of Enzymes Involved in the Formation of Acetate and Butyrate vol. 47, (1984), pp. 1277-1283.

[48] M.G.N. Hartmanis, T. Klason, S. Gatenbeck, Uptake and activation of acetate and butyrate in Clostridium acetobutylicum, Appl. Microbiol. Biotechnol. 20 (1984) 66-71, https://doi.org/10.1007/BF00254648.

[49] W. Andersch, H. Bahl, G. Gottschalk, Level of enzymes involved in acetate, butyrate, acetone and butanol formation by Clostridium acetobutylicum, Eur. J. Appl Microbiol. Biotechnol. 18 (1983) 327-332, https://doi.org/10.1007/BF00504740.

[50] R. Gallardo, C. Faria, L.R. Rodrigues, M.A. Pereira, M.M. Alves, Anaerobic granular sludge as a biocatalyst for 1,3-propanediol production from glycerol in continuous bioreactors, Bioresour. Technol. 155 (2014) 28-33, https://doi.org/10.1016/j. biortech.2013.12.008

[51] G. Kumar, P. Bakonyi, T. Kobayashi, K.Q. Xu, P. Sivagurunathan, S.H. Kim, G. Buitrón, N. Nemestóthy, K. Bélafi-Bakó, Enhancement of biofuel production via microbial augmentation: the case of dark fermentative hydrogen, Renew. Sustain. Energy Rev. 57 (2016) 879-891, https://doi.org/10.1016/j.rser.2015.12.107.

[52] S. Pattra, C.H. Lay, C.Y. Lin, S. O-Thong, A. Reungsang, Performance and population analysis of hydrogen production from sugarcane juice by non-sterile continuous stirred tank reactor augmented with Clostridium butyricum, Int. J. Hydrogen Energy (2011) 8697-8703, https://doi.org/10.1016/j.ijhydene.2010.05. 120.

[53] H.N. Gavala, I. Angelidaki, B.K. Ahring, Kinetics and modeling of anaerobic digestion process, Adv. Biochem. Eng. Biotechnol. 81 (2003) 57-93, https://doi.org/ 10.1007/3-540-45839-5.

[54] S. Ge, J.G. Usack, C.M. Spirito, L.T. Angenent, Long-Term n-caproic acid production from yeast-fermentation beer in an anaerobic bioreactor with continuous product extraction, Environ. Sci. Technol. 49 (2015) 8012-8021, https://doi.org/10.1021/ acs.est.5b00238.

[55] G. Muyzer, E.C. Dewaal, A.G. Uitterlinden, Profiling of complex microbial populations by denaturing gradient gel electrophoresis analysis of polymerase chain reaction-amplified genes coding for 16S rRNA, Appl. Environ. Microbiol. 59 (1993) 695-700 doi:0099-2240/93/030695-06\$02.00/0.

[56] N.T. Dinh, K. Hatta, S.H. Kwon, A.P. Rollon, K. Nakasaki, Changes in the microbial community during the acclimation stages of the methane fermentation for the treatment of glycerol, Biomass Bioenergy 68 (2014) 240-249, https://doi.org/10. 1016/j.biombioe.2014.06.022.

[57] X.H. Yi, J. Wan, Y. Ma, Y. Wang, Characteristics and dominant microbial community structure of granular sludge under the simultaneous denitrification and methanogenesis process, Biochem. Eng. J. 107 (2016) 66-74, https://doi.org/10. 1016/j.bej.2015.12.003.

[58] S.C. Santos, P.R.F. Rosa, I.K. Sakamoto, M.B. Amâncio Varesche, E.L. Silva, Hydrogen production from diluted and raw sugarcane vinasse under thermophilic anaerobic conditions, Int. J. Hydrogen Energy 39 (2014) 9599-9610, https://doi. org/10.1016/j.ijhydene.2014.04.104.

[59] Y. Yuan, S. Wang, Y. Liu, B. Li, B. Wang, Y. Peng, Long-term effect of pH on shortchain fatty acids accumulation and microbial community in sludge fermentation systems, Bioresour. Technol. 197 (2015) 56-63, https://doi.org/10.1016/j. biortech.2015.08.025.

[60] R.M. Myers, S.G. Fischer, L.S. Lerman, T. Maniatis, Nearly all single base substitutions in DNA fragments joined to a GC- clamp can be detected by denaturing gradient gel electrophoresis, Nucleic Acids Res. 13 (1985) 3131-3145 http://www. ncbi.nlm.nih.gov/cgi-bin/Entrez/referer?http://www.ncbi.nlm.nih.gov/htbinpost/Omim/getmim\%3Ffield = medline_uid\&search $=4000972$.

[61] C.R. Jackson, C.R. Jackson, E.E. Roden, E.E. Roden, P.F. Churchill, P.F. Churchill, Denaturing gradient gel electrophoresis can fail to separate 16S rDNA fragments with multiple base differences, Mol. Biol. Today 1 (2000) 49-51.

[62] D. Xing, N. Ren, M. Gong, J. Li, Q. Li, Monitoring of microbial community structure and succession in the biohydrogen production reactor by denaturing gradient gel electrophoresis (DGGE), Sci. China C Life Sci. 48 (2005) 155-162, https://doi.org/ 10.1007/BF02879668.

[63] T.M. LaPara, C.H. Nakatsu, L.M. Pantea, J.E. Alleman, Stability of the bacterial communities supported by a seven-stage biological process treating pharmaceutical wastewater as revealed by PCR-DGGE, Water Res. 36 (2002) 638-646, https://doi org/10.1016/S0043-1354(01)00277-9.

[64] L. Wittebolle, W. Verstraete, N. Boon, The inoculum effect on the ammonia-oxidizing bacterial communities in parallel sequential batch reactors, Water Res. 43 (2009) 4149-4158, https://doi.org/10.1016/j.watres.2009.06.034.

[65] M. Marzorati, L. Wittebolle, N. Boon, D. Daffonchio, W. Verstraete, How to get more out of molecular fingerprints: practical tools for microbial ecology, Environ. Microbiol. 10 (2008) 1571-1581, https://doi.org/10.1111/j.1462-2920.2008. 01572.x.

[66] W. Dejonghe, N. Boon, D. Seghers, E.M. Top, W. Verstraete, Bioaugmentation of soils by increasing microbial richness: missing links, Environ. Microbiol. 3 (2001) 649-657, https://doi.org/10.1046/j.1462-2920.2001.00236.x.

[67] D.H. Kim, S. Jang, Y.M. Yun, M.K. Lee, C. Moon, W.S. Kang, S.S. Kwak, M.S. Kim, Effect of acid-pretreatment on hydrogen fermentation of food waste: microbial community analysis by next generation sequencing, Int. J. Hydrogen Energy (2014) 16302-16309, https://doi.org/10.1016/j.ijhydene.2014.08.004.

[68] M.V. Reddy, S. Hayashi, D. Choi, H. Cho, Y.C. Chang, Short chain and medium chain fatty acids production using food waste under non-augmented and bio-augmented conditions, J. Clean. Prod. 176 (2018) 645-653, https://doi.org/10.1016/j. jclepro.2017.12.166.

[69] L. Leng, P. Yang, Y. Mao, Z. Wu, T. Zhang, P.H. Lee, Thermodynamic and physiological study of caproate and 1,3-propanediol co-production through glycerol fermentation and fatty acids chain elongation, Water Res. (2017), https://doi.org/10. 1016/j.watres.2017.02.023. 